\title{
CD271 is a negative prognostic factor and essential for cell proliferation in lung squamous cell carcinoma
}

\author{
Mai Mochizuki ${ }^{1}$ Mao Nakamura ${ }^{2} \cdot$ Rie Sibuya ${ }^{1}$ - Toshimasa Okazaki ${ }^{3}$ Jiro Abe ${ }^{3}$ - Takayuki Nakagawa' \\ Satomi Takahashi ${ }^{3} \cdot$ Tomoko Yamazaki $^{4} \cdot$ Takayuki Imai $^{5} \cdot$ Atsushi Takano $^{6,7} \cdot$ Hiroyuki Ito $^{8} \cdot$ Tomoyuki Yokose $^{9}{ }^{9}$. \\ Yohei Miyagi $^{10} \cdot$ Yataro Daigo $^{6,7} \cdot$ Ikuro Sato $^{11} \cdot$ Kennichi Satoh $^{1,12} \cdot$ Kazuo Sugamura $^{2} \cdot$ Kazunori Yamaguchi $^{2}$. \\ Keiichi Tamai ${ }^{1}$
}

Received: 26 August 2018 / Revised: 26 February 2019 / Accepted: 28 February 2019 / Published online: 24 April 2019

(c) United States \& Canadian Academy of Pathology 2019

\begin{abstract}
Squamous cell carcinoma is a major type of cancer in the lung. While several therapeutic target molecules for lung adenocarcinoma have been identified, little is known about lung squamous cell carcinoma (LSCC). We recently reported that CD271 (p75 neurotrophin receptor) serves as a marker for tumor initiation and is a key regulator of cell proliferation in hypopharyngeal squamous cell carcinoma. In this study, we found that CD271 was also expressed in squamous cell carcinoma, but not in adenocarcinoma, of several tissues, including the lung, and the expression of CD271 was associated with a poor prognosis in LSCC. To examine CD271's role in LSCC, we established xenograft cell lines from LSCC patients. Within the sorted live LSCC cell population, the CD271 $1^{\text {high }}$ cells were primarily cycling through the $\mathrm{G}_{2} / \mathrm{M}$ phase, while the CD271 ${ }^{\text {low }}$ cells were mostly in the $\mathrm{G}_{0}$ phase. CD271 knockdown in the LSCC cells completely suppressed their proliferation and tumor-formation capability, and increased their cell-cycle arrest in the $\mathrm{G}_{0}$ phase. In the CD271-knockdown cells, ERKphosphorylation was decreased, while no change was observed in the IкB $\alpha$-phosphorylation, p65-phosphorylation, or Aktphosphorylation. Treatment with the MEK inhibitor U0126 decreased the LSCC cells' proliferation capability. Microarray analysis revealed that CD271 knockdown attenuated the RAS-related pathways. The knockdown of TrkB, which forms a heterodimer with CD271 and accelerates its downstream signaling, partially inhibited the LSCC cell proliferation. These results indicated that LSCC exclusively depends on CD271 for cell proliferation, in part through ERK-signaling activation, and CD271 is a promising target for LSCC therapy.
\end{abstract}

\section{Introduction}

Lung cancer is the most common cause of cancer deaths worldwide [1]. Non-small cell lung cancer (NSCLC) accounts for more than $80 \%$ of all lung cancer. Less than $10 \%$ of the patients with stage IV NSCLC survive 5 years after the diagnosis, while the 5-year survival rate of those with stage IA is as high as $80 \%$. Multimodal treatment including surgery, chemotherapy, and radiotherapy, does not satisfactorily improve the prognosis [2].

Supplementary information The online version of this article (https:// doi.org/10.1038/s41374-019-0246-5) contains supplementary material, which is available to authorized users.

Keiichi Tamai

tamaikeiichi@med.tohoku.ac.jp

Extended author information available on the last page of the article
There are two main subtypes of NSCLC, lung adenocarcinoma and lung squamous cell carcinoma (LSCC), which account for $40 \%$ and $25-30 \%$ of the cases, respectively [3]. The great majority of patients with LSCC are current or former smokers; in contrast, a growing proportion of adenocarcinoma patients are never-smokers or former light smokers [4]. While several druggable oncogene targets have been found for the never-smoker subset of adenocarcinoma [5], limited therapeutic targets are available for advanced-stage LSCC because of the complexity of genomic alteration [4].

CD271, also known as p75 neurotrophin receptor (p75NTR), is a member of the tumor necrosis factor receptor (TNFR) superfamily, which binds to several ligands, including nerve growth factor (NGF), brain-derived neurotrophic factor (BDNF), nuerotrophin-3 (NT3), and neurotrophin-4 (NT4) [6]. CD271 cooperates with receptor tyrosine kinases of the Trk family to form high-affinity receptors for 
neurotrophins and to activate a signaling pathway for cell proliferation $[7,8]$. Notably, TrkB has been shown to contribute to the promotion of cell proliferation in LSCC [9].

We previously demonstrated that basal cells of the normal squamous epithelium in the pharynx express CD271, and that CD271 serves as a cancer stem-cell marker of hypopharyngeal cancer and regulates cell proliferation and motility in this disease [10, 11]. Similarly, CD271 is expressed in basal cells of the normal squamous epithelium of the esophagus, and serves as a stem-cell marker of esophageal cancer [12, 13]. These findings suggested that CD271 is involved in the development of squamous cell carcinoma in various organs.

Here, we demonstrated that CD271 is preferentially expressed in squamous cell carcinoma but not in adenocarcinoma of the lung and other tissues, and plays critical roles in the cancer cell proliferation in LSCC.

\section{Materials and methods}

\section{Animal study}

The animal experimental protocols were approved by the Miyagi Cancer Center Animal Care and Use Committee.

\section{Tissue specimens}

We collected primary cancer tissues from patients who had undergone surgical lobectomy or pneumonectomy at Miyagi Cancer Center (Miyagi, Japan) and Kanagawa Cancer Center (Yokohama, Japan), after obtaining informed consent. A total of 156 resected tumor specimens derived from 110 lung squamous cell carcinoma patients (2004-2013, absence of residual cancer both macroscopically and histologically in all cases), 25 lung adenocarcinoma patients (2010), 20 lung adenosquamous carcinoma patients (2006-2017), and one carcinoma in situ patient were preserved at the Miyagi Cancer Center Tissue Bank (MCC-TB). A total of 339 resected tumor specimens derived from 302 adenocarcinoma patients and 37 squamous cell carcinoma patients (2006-2011) were preserved at the Kanagawa Cancer Center Biospecimen Center (KCC-BSC). The tissues from cervical cancer, penile cancer, vulvar cancer, and esophageal cancer were also obtained from the surgical specimens at the Miyagi Cancer Center. The use of these clinical materials was approved by the institutional ethics committees. All cases were classified histopathologically according to the World Health Organization Classification of Tumors 2004 criteria, and the stage of lung squamous cell carcinoma was classified according to the 7th edition of the UICC TNM staging system. Relapse-free-survival was defined as the interval between the date of surgery and the date of recurrence or the last contact. We reviewed the patients' medical records for the following clinicopathological factors: age, gender, pathological $\mathrm{T}, \mathrm{N}$, and $\mathrm{M}(\mathrm{pT}, \mathrm{pN}$, and pM) classification, histological type, pleural invasion, vascular invasion, and lymphovascular invasion. All patients gave written informed consent for inclusion in the study.

\section{Scoring system for immunohistochemistry}

To evaluate the immunohistochemical results, positivity of staining in cancer area was assessed. The positivity was classified into three grades; "negative" was defined as $<10 \%$ positive, "weak" as 10-29\%, and "strong" as 30-100\% (see Supplementary Fig. S2A) or two grades; "negative" as $<10 \%$ positive, "positive" as 10-100\% (see Fig. 7a). Stains were evaluated separately by at least 2 of us (M.M. and K.T.), and the interobserver variability was very low ( $<5 \%$ of cases).

\section{Establishment of patient-derived xenograft (PDX) cell lines}

Three PDX cell lines named MCC121, MCC138, and MCC148 were newly established by serial xenografts of tumor tissues derived from human primary LSCC patients, as described previously with minor modification [10]. In brief, fresh tumor specimens of LSCC obtained from the Miyagi Cancer Center (MCC) were transplanted into NOD/ $\mathrm{SCID} / \gamma \mathrm{c}^{\text {null }}$ (NOG) mice (purchased from In-Vivo Science, Tokyo, Japan), and tumor formation was monitored weekly. When the tumors reached over $10 \mathrm{~mm}$ in diameter, the mice were sacrificed, and the tumors were divided into three pieces for single-cell digestion, formalin fixation for histology, and serial passage in mice.

\section{Cell lines}

The cell lines used were the three LSCC PDX cell lines (MCC121c, MCC138c, and MCC148c) described above and another LSCC-derived LK-2 cell line (purchased from RIKEN BioResource Center, Japan). The three PDX-cell lines were maintained in vitro in DMEM supplemented with $10 \%$ fetal bovine serum (FBS), $0.4 \mu \mathrm{g} / \mathrm{ml}$ hydrocortisone, $2.5 \mu \mathrm{M}$ Y27632, $100 \mathrm{unit} / \mathrm{ml}$ penicillin and $100 \mu \mathrm{g} / \mathrm{ml}$ streptomycin (Nakalai Tesque, Japan). The LK-2 cell line was maintained in RPMI medium supplemented with $10 \%$ fetal FBS and $1 \%$ penicillin-streptomycin. The three PDX cell lines were passaged at least 10 times in vitro before being used in experiments.

\section{Antibodies}

An APC-conjugated anti-human CD271 (NGFR) antibody (clone ME20.4, Biolegend, San Diego, CA) and Alexa Fluor ${ }^{\circledR}$ 488-conjugated anti-human Ki67 antibody (clone Ki67, 
Biolegend) were used for flow cytometry analyses. The following antibodies were used for Western blotting analyses: anti-phospho-p44/42 MAPK (ERK1/2, Thr202/Tyr204) (clone 20G11, Cell Signaling Technologies, Danvers, MA, USA), anti-ERK (clone 137E5, Cell Signaling), anti-c-myc (clone 9E10, Santa Cruz Biotechnology, Dallas, TX, USA), anti- $\alpha-$ tubulin (B-5-1-2, Santa Cruz Biotechnology), anti-phosphoNF-кB p65 (S536) and anti-NF-кB p65 (93H1 and D14E12,

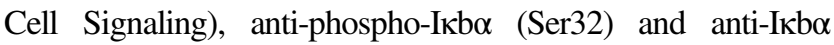
(14D4 and L35A5, Cell Signaling), and anti-phospho-Akt (S473) and anti-Akt (pan, Cell Signaling). The following antibodies were used for immunohistochemistry analyses: antiCD271 (C40-1457, BD Biosciences, Franklin Lakes, NJ, USA) and anti-Ki67 (clone SP6, Abcam, UK), with 3,3'-diaminobenzidine (DAB) staining.

\section{Small interfering RNAs}

CD271 siRNAs \#1 (HSS107179) and \#2 (HSS107181), TrkB siRNAs \#1 (HSS107338) and \#2 (HSS107339), and non-silencing control siRNA (12935-300) were purchased from Invitrogen (Carlsbad, CA, USA). The siRNA transfections were performed using Lipofectamine ${ }^{\circledR}$ RNAiMAX Reagent (Life Technologies, CA, USA) in antibiotic-free medium for $48 \mathrm{~h}$. The siRNA knockdown efficiencies were confirmed by flow cytometry analysis or real-time PCR.

\section{Immunohistochemistry}

Paraffin-embedded, formalin-fixed, 3- $\mu$ m-thick (MCC-TB) or 5- $\mu$ m-thick (KCC-BSC) tissue sections from human NSCLC patients were deparaffinized in xylene, and rehydrated by washing with a series of ethanol dilutions and distilled water. Heat-induced epitope retrieval was performed by microwaving the sections in a $\mathrm{pH} 9.0$ targetretrieval solution (Dako, Denmark). Endogenous peroxidases were blocked with $3 \% \mathrm{H}_{2} \mathrm{O}_{2}$. The sections were incubated with anti-human CD271 $(1: 5,000)$ for $20 \mathrm{~min}$ or with anti-Ki67 (1:200) for $60 \mathrm{~min}$, at $37^{\circ} \mathrm{C}$. The $\mathrm{CD} 271-$ stained sections were incubated for $15 \mathrm{~min}$ with mouse LINKER (Dako), followed by incubation with the secondary antibody. The specimens were treated with DAB Chromogen (EnVision ${ }^{\mathrm{TM}}$ Detection SystemsPeroxidase/ DAB, Rabbit/Mouse, Dako) and counterstained with hematoxylin.

\section{Immunofluorescence staining of CD271 and pERK}

The paraffin-embedded, formalin-fixed, 3- $\mu \mathrm{m}$ tissue sections from human lung squamous cell carcinoma patients were deparaffinized, and then epitope retrieval was performed as described above. The sections were incubated with anti-human CD271 (1:5000) and anti-pERK (1:400) primary antibodies overnight at $4{ }^{\circ} \mathrm{C}$. The sections were then incubated for $1 \mathrm{~h}$ with Alexa Fluor 594 goat anti-rabbit IgG (1:200, Invitrogen), goat anti-mouse IgG $(\mathrm{H}+\mathrm{L}) \mathrm{HRP}$ conjugate (1:200, Invitrogen), and DAPI solution (1:1000, Dojindo, Japan), and the CD271 signals were amplified using a Tyramide Signal Amplification Kit (ThermoFisher, MA, USA), according to the manufacturer's protocol. Images were obtained with a fluorescence microscope (Nikon A1, Nikon, Japan).

\section{ERK inhibition}

The MEK/ERK inhibitor U0126 was purchased from InvivoGen (San Diego, CA, USA) and solubilized in DMSO. The indicated concentration of inhibitor solution or DMSO was added to cells in complete medium, and the cells were incubated for $48 \mathrm{~h}$.

\section{Quantitative real-time PCR}

Total RNA was extracted from LSCC cell line (MCC148c) cells using the RNeasy Mini Kit (Qiagen, Valencia, CA) or Sepasol-RNA I Super G (Nakalai Tesque, Japan), and reverse transcribed using a PrimeScript II cDNA Synthesis Kit (Takara Bio, Japan). Real-time PCR was performed using the Brilliant III Ultra-Fast SYBR Green QPCR Master Mix (Agilent Technologies). B-actin was used as an endogenous reference gene. The primer sequences used for real-time PCR were as follows. B-actin: F-ccaaccgcgagaagatga R-tccatcacgatgccagtg, CD271 F-tgctgttgctgcttctgg R-ctcacacacggtctggttg, c-MYC: F-caccagcagggactctga R-gatccagactctgacctttgc, CDKN1C: F-gcggcgatcaagaagctgt R-atcgcccgacgacttctca, TrkA: F-tggtcatctgcggactca R-agagggtgccaggcagat, TrkB: Fcaattgtggtttgccatctg R-tgcaaaatgcacagtgaggt, and TrkC: Fatgaggaacctgaggtccag R-cgggaaggcttattggattc.

\section{In vivo tumorigenesis}

The tumor-formation assay was performed as described previously with minor modifications [10]. Under aseptic conditions, tumors were cut into small fragments, and finely minced with a sterile scalpel. After being washed with PBS $(-)$, the tumor tissue was incubated in a solution containing PBS(-), $1 \mathrm{mg} / \mathrm{ml}$ DNase1 (Roche), and $1 \mathrm{mg} / \mathrm{ml} \mathrm{Col-}$ lagenase/Dispase (Roche) at $37^{\circ} \mathrm{C}$ for 2 or $3 \mathrm{~h}$, until complete digestion had occurred. The cells were then passed through a 40- $\mu$ m nylon mesh, and washed three times with PBS $(-)$. After centrifugation, the pool of single cells was divided, and the cells were used for flow cytometry analyses and cell-line establishment. To exclude dead cells, 7-Amino Actinomycin D (7-AAD, Sigma) was used. For the xenotransplantation of cells in which CD271 was knocked down cells using siRNA [14], MCC148c cells maintained in vitro 
were transiently transfected with siCD271\#1, siCD271\#2, or sicontrol. Forty-eight hours after transfection, the cells were trypsinized, and the live populations were stained and sorted as described above. The cells were suspended in 50 $\mu \mathrm{l}$ of DMEM supplemented with 10\% FBS and an equal volume of Matrigel matrix (BD Biosciences) at $4{ }^{\circ} \mathrm{C}$, and then injected into NOG mice with a 1-ml syringe. Each mouse received an injection of control cells in the right side, and of RNAi-treated cells in the left side. Tumor formation was monitored weekly. The tumor volume is calculated by the following formula; $1 / 2$ (Length $\times$ Width $^{2}$ ).

\section{Gene expression profiling}

Whole genome expression profiling of CD271-knockdown and control cells was performed with four biological replicates. RNA from MCC148c cells was purified using RNeasy Mini Kits and QIAshredder columns (Qiagen, Canada). Microarray analysis was performed using SurePrint G3 Human Gene Expression $8 \times 60 \mathrm{~K}$ Microarray Kits (Agilent Technologies, CA) and the Low Input Quick Amp Labeling Kit (Agilent Technologies) according to the manufacturer's protocols. After hybridization and washing, the processed slides were scanned with the Agilent Microarray Scanner (Agilent Technologies), and the acquired array images were analyzed using Agilent Feature Extraction Software (Agilent Technologies). Normalization and subsequent data processing were performed using R statistical software.

\section{Gene-set enrichment analysis (GSEA)}

Quantile normalized expression data of CD271-knockdown and control cells were analyzed with GSEA (Broad Institute, http://www.broadinstitute.org/gsea/index.jsp) and the oncogenic signatures gene sets (C6).

\section{Flow cytometry analysis}

Cells were incubated with the appropriate antibody or control mouse IgGк $\kappa_{1}$ for $30 \mathrm{~min}$ at $4{ }^{\circ} \mathrm{C}$, washed twice, and subsequently analyzed using a FACSCanto II (Becton Dickinson, CA).

\section{Cell-cycle analysis}

For the cell-cycle analysis of CD271 $1^{\text {high }}$ and CD271 ${ }^{\text {low }}$ cells, live populations of MCC148c cells stained with an antiCD271 antibody were first sorted with a FACSAria II. To exclude dead cells, 7-AAD (Sigma) was used. To analyze CD271-knockdown cells using siRNA, the MCC148c cells were transiently transfected with siCD271\#1, siCD271\#2, or sicontrol. Forty-eight hours after transfection, the cells were trypsinized, and then fixed with $70 \%$ ethanol at $-20^{\circ} \mathrm{C}$. The fixed cells were stained with anti-Ki67 (1:60) and $10 \mu \mathrm{g} / \mathrm{ml}$ propidium iodide (PI). The stained cells were then analyzed by flow cytometry.

\section{Western blotting}

Cells were washed once with PBS(-), suspended in SDSloading buffer $(100 \mathrm{mM}$ Tris- $\mathrm{Cl} \mathrm{pH} 6.8,4 \%$ sodium dodecyl sulfate, $0.2 \%$ bromophenol blue, $20 \%$ glycerol, $2 \% \beta$ mercaptoethanol), sonicated for $5 \mathrm{~min}$, and boiled for $5 \mathrm{~min}$, and then subjected to SDS-PAGE (Wako, Japan). The separated proteins were transferred onto a PVDF membrane (Millipore, Billerica, MA), and then blocked with 5\% BSA in TTBS for $60 \mathrm{~min}$ at room temperature. The membrane was then incubated with 1:1000-diluted primary antibody and then with HRP-conjugated anti-mouse or anti-rabbit antibody (Cell Signaling Technology) as recommended by the manufacturers. Primary antibody binding was detected using a Clarity Western ECL Substrate (Bio-Rad, Richmond, CA), and images were captured by a CCD camera (Fuji Film, Tokyo, Japan).

\section{MTT assay}

A total of 3000 cells were plated in $0.1 \mathrm{ml}$ complete medium in a 96-well plate. At the indicated times, MTT assay reagent (Roche) was added to each well according to the manufacturer's protocol. The absorbances at $575 \mathrm{~nm}$ and $650 \mathrm{~nm}$ (background measurement) were determined using a plate reader (VersaMax ELISA Microplate Reader, Molecular Devices, Sunnyvale, CA, USA). Five replicate wells were assayed for each condition, and the S.D. was determined.

\section{In vitro scratch assays}

Cells were cultured on a 24-well tissue culture plate (BD Biosciences) until confluent and then treated with $5 \mu \mathrm{g} / \mathrm{ml}$ mitomycin C (Wako, Japan) for $3 \mathrm{~h}$. The cells were then gently scratched with a pipette tip, washed with medium, and incubated with fresh medium for $24 \mathrm{~h}$.

\section{Statistical analysis}

Statistical analysis was performed using GraphPad Prism vision 7.03 (GraphPad Software, La Jolla, CA, USA) and R software version 3.2.2. The differences between two groups were analyzed by an unpaired $t$-test with Welch's correction and Fisher's exact test. $p$-values $<0.05$ were considered to be statistically significant. The analysis of a relapse-free survival was conducted with a Kaplan-Meier method and a log-rank test was used to evaluate the difference between two groups ("CD271-negative" versus "CD271-positive"). 
For multivariate analyses of significant factors identified by the log-rank test, we used Cox's proportional hazards.

\section{Results}

\section{CD271 is expressed in lung squamous cell carcinoma and defines proliferating cells}

We first searched for the CD271 immunohistochemistry data in the Tissue Atlas (https://www.proteinatlas.org/ tissue). CD271 was positive in squamous cell carcinoma (e.g., lung, head-and-neck, and cervix), while almost no CD271 staining was observed in adenocarcinoma (lung, stomach, and colon) (data not shown). Thus, we examined whether CD271 is expressed in the squamous cell carcinoma of certain organs. We stained normal tissues and squamous cell carcinoma specimens of the lung, vulva, penis, and esophagus using an anti-CD271 antibody. In the normal tissues, the CD271-positive cells were localized to the basal layer of the bronchiole, bronchus, penile, vulvar, and esophagus epithelium, but CD271 was not expressed in the alveolus (Fig. 1a). In squamous cell carcinoma tissues, CD271 was clearly expressed in cancer cells adjacent to the stroma (Fig. 1b). Ki67, a cell proliferation marker, was colocalized with CD271 in cancer cells of the lung, penis, vulva, and esophagus (Fig. 1b). We also stained lung squamous carcinoma specimens with an antibody for MCM7, an established cell-proliferation marker, and found that CD271 was clearly colocalized with the MCM7positive cells (Supplementary Fig. S1).

To confirm the expression of CD271 in lung cancer, we stained surgical specimens of human lung squamous cell carcinoma, lung squamous cell carcinoma in situ, and adenocarcinoma obtained from the Miyagi Cancer Center tissue bank (MCC-TB) with anti-CD271 and anti-Ki67 antibodies (squamous cell carcinoma; Fig. 1b, a-d, squamous cell carcinoma in situ; Fig. 2a, a-d, adenocarcinoma; Fig. 2a, i-l), or with the anti-CD271 antibody and HE staining (lung adenosquamous carcinoma; Fig. 2a, e-h). In squamous cell carcinoma in situ, both CD271-positive and Ki67-positive cells were observed in the basal layer, similar to squamous cell carcinoma (Fig. 2a, a-d). Of the squamous cell carcinoma specimens, $61.8 \%$ (68/110) expressed CD271 (Table 1a). In adenocarcinoma, however, no CD271-positive cells were detected in 25 specimens (Table 1a; Fig. 2a). In adenosquamous carcinoma, 55.0\% $(11 / 20)$ of the specimens expressed CD271 (Table 1), and this expression was seen in the squamous cell carcinoma region but not in the adenocarcinoma region (see Fig. 2a, e-h). We also stained a tissue array of 302 adenocarcinomas and 37 squamous cell carcinomas preserved at the KCCBSC. Of the squamous cell carcinoma specimens, $35.1 \%$
(13/37) were CD271-positive (Table 1b; Fig. 2b), whereas only $1.7 \%(5 / 302)$ of the adenocarcinoma specimens were CD271-positive.

To characterize the CD271-positive cells in LSCC, we established a patient-derived xenograft (PDX) cell line named MCC148c, which expressed high CD271, by transplanting an LSCC specimen into immunodeficient $\mathrm{NOD} / \mathrm{scid} / \gamma \mathrm{cnull}$ (NOG) mice as described in the Materials and methods section. Immunostaining of the MCC148c cells showed that the CD271-positive cells tended to be positive for Ki67 (Fig. 3a), suggesting that they were proliferating in vivo. We then compared the in vitro proliferative capability between the CD271 $1^{\text {high }}$ and $\mathrm{CD} 271^{\text {low }}$ cell populations sorted from MCC148c. Flow cytometry analysis showed that the $\mathrm{CD} 271^{\text {high }}$ cells were primarily cycling through the $\mathrm{G}_{2} / \mathrm{M}$ phase, while the $\mathrm{CD} 271^{\text {low }}$ cells were primarily in the $\mathrm{G}_{0}$ phase, compared with the original MCC148c cell population (Fig. 3b). These findings indicated that the CD271 ${ }^{\text {high }}$ LSCC cells were proliferative both in vitro and in vivo.

\section{CD271 knockdown decreases cell proliferation and tumorigenicity in LSCC}

To investigate the contribution of CD271 to cell proliferation in LSCC, we analyzed four LSCC cell lines: LK2 and our three PDX cell lines, MCC148c, MCC121c, and MCC138c. We knocked down CD271 in each cell line by introducing small interfering RNAs (siRNAs). Two CD271targeting siRNAs (siCD271 \#1 and \#2) were transfected into the cell lines, and the suppression of CD271 expression was confirmed by flow cytometry (Fig. 3c). CD271's expression was high in MCC121c and MCC148c cells, and low in MCC138c and LK2 cells. We then examined the proliferation of these LSCC cell lines using MTT assays. The cell proliferation was completely suppressed by the CD271-knockdown in MCC148c cells, strongly suppressed in MCC121c cells, and slightly suppressed in MCC138c and LK2 cells (Fig. 3d). These results indicated that CD271 helps to promote cell proliferation in vitro, and the strength of its promoting effect depends on its expression level in these LSCC cell lines.

We next investigated the effect of CD271 knockdown on the proliferation and tumorigenicity of LSCC cells in vivo. MCC148c cells, in which the CD271 expression was the highest among the four LSCC cell lines, were transfected with the two types of CD271 siRNAs (siCD271 \#1 and \#2) or control RNAs (sicontrol), and then injected into NOG mice. The sicontrol-transfected cells formed tumors at eleven of sixteen injection sites (11/16), whereas both the siCD271\#1-transfected and the siCD271\#2-transfected cells formed no tumors in eight injection sites (0/8), at 19-week after injection (Fig. 4a, b; Table 2). 
A
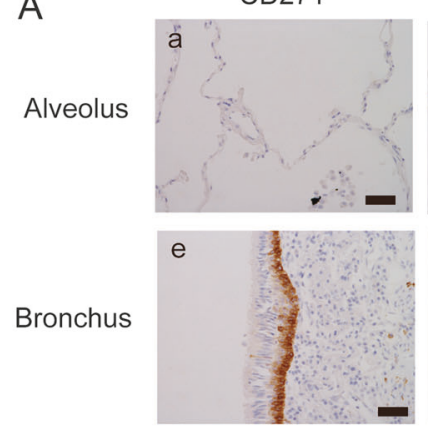

Ki67
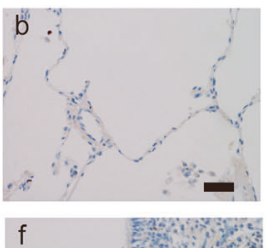
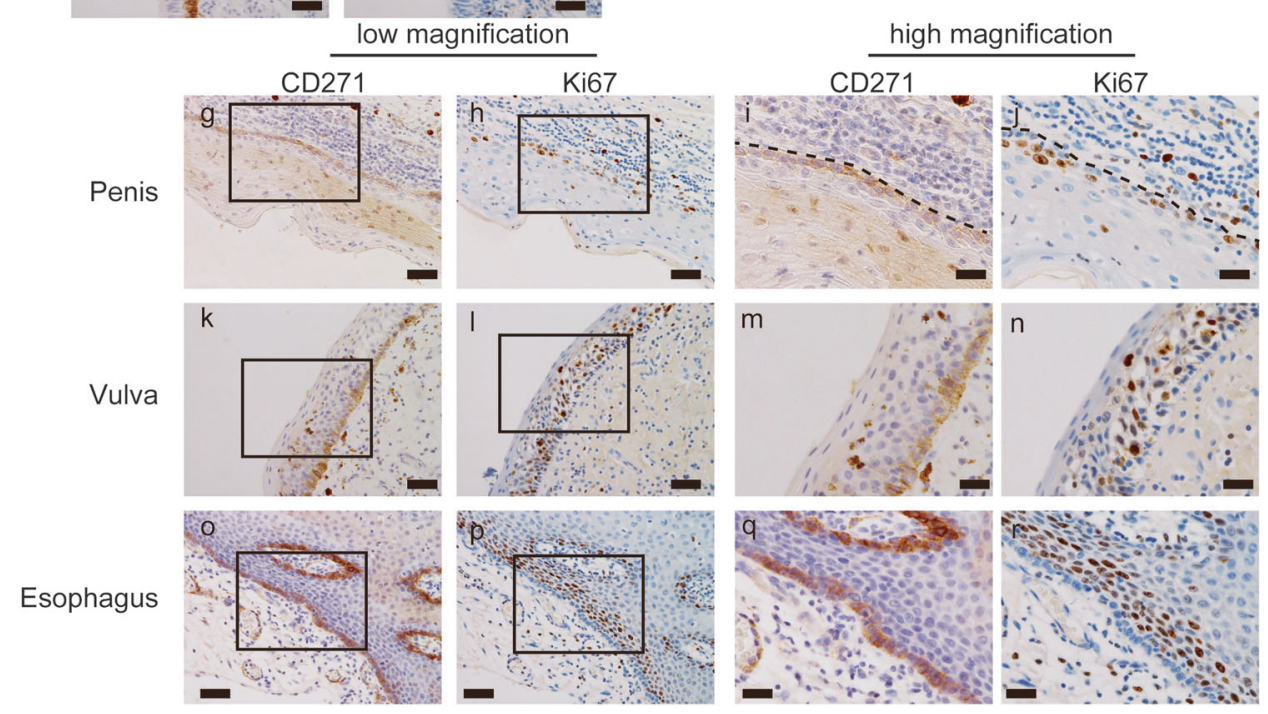

B
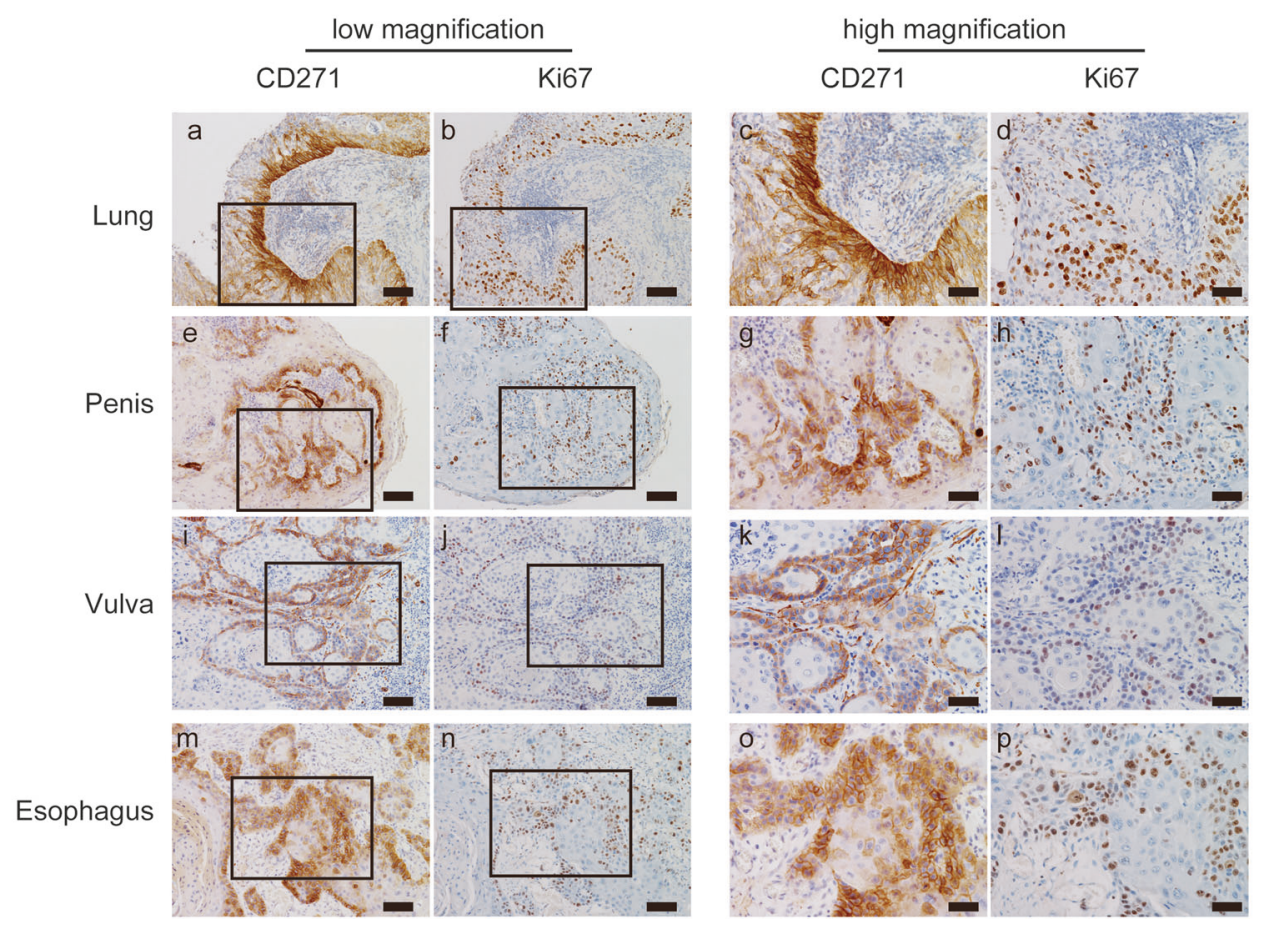

CD271
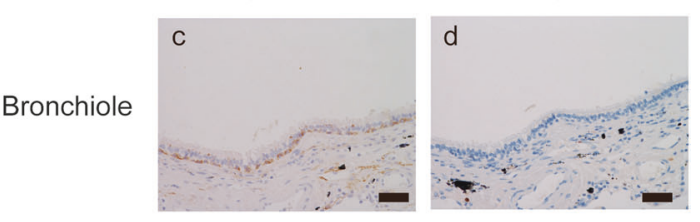

Fig. 1 a Representative images of anti-CD271 and Ki67 immunohistochemically stained normal tissue from the lung alveolus (a, b), bronchiole (c, d), and bronchus (e, f), and the penis $(\mathbf{g}, \mathbf{h})$, vulva $(\mathbf{i}, \mathbf{j})$, and esophagus $(\mathbf{k}, \mathbf{l})$. b Representative images of anti-CD271 and anti-

Ki67 immunohistochemically stained SCC specimens from the lung (a-d), penis (e-h), vulva (i-l), and esophagus $(\mathbf{m}-\mathbf{p})$. Bar for lowmagnification images, $100 \mu \mathrm{m}$. Bar for high-magnification images, $50 \mu \mathrm{m}$ 
A

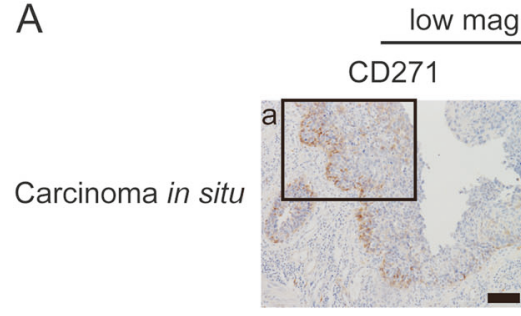

HE

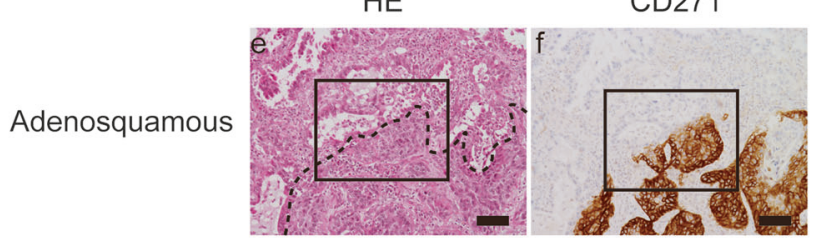

CD271

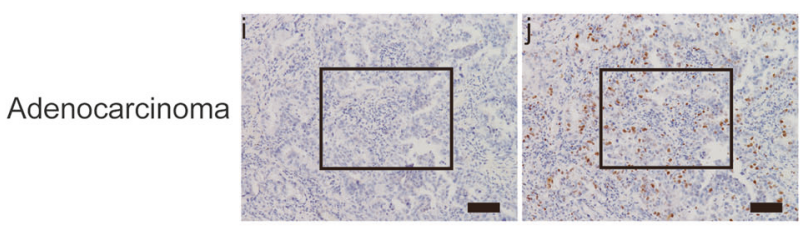

B
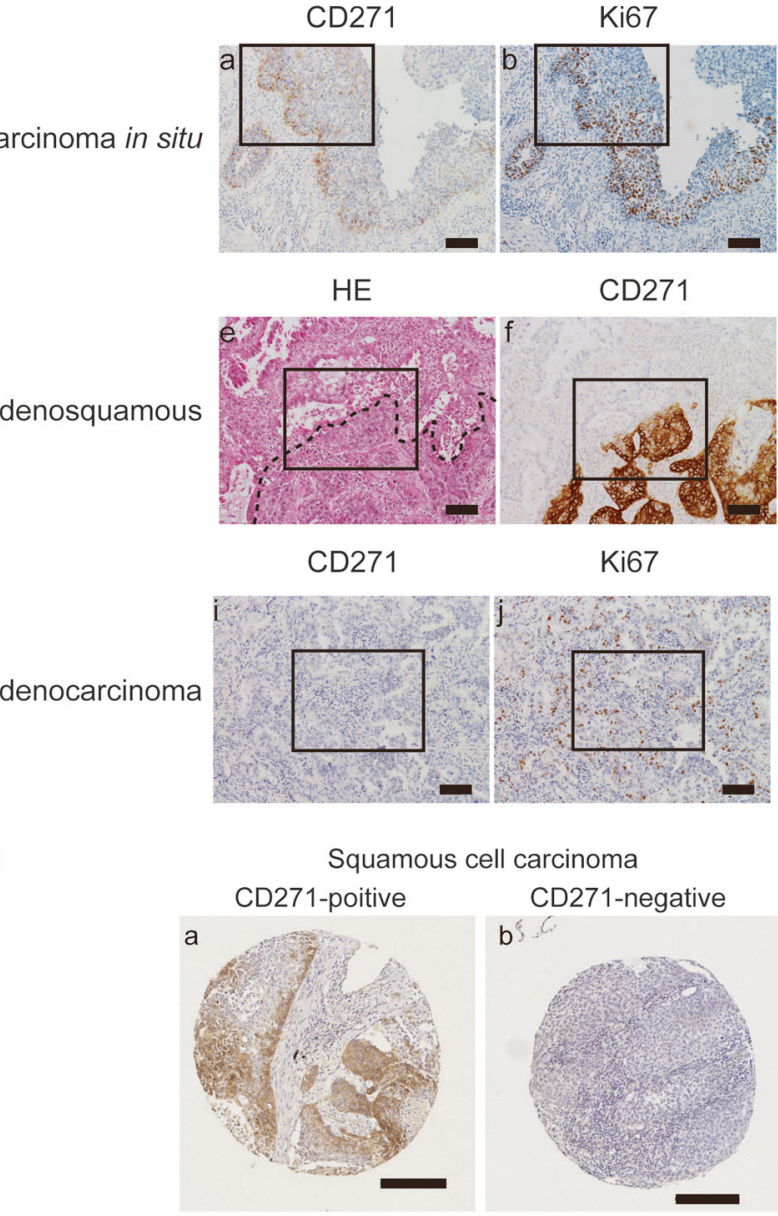

CD271

Ki67

ve

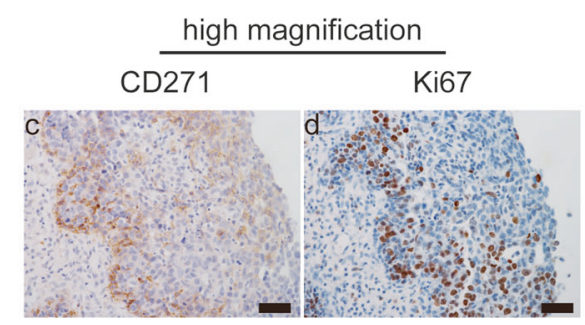

HE

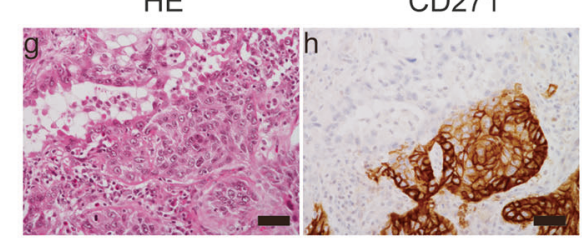

CD271

Ki67

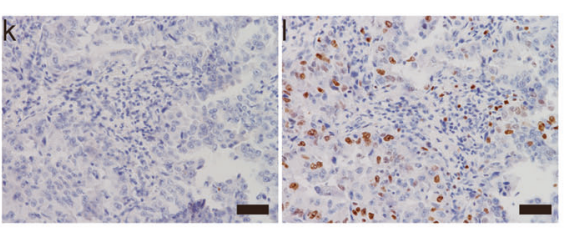

Adenocarcinoma

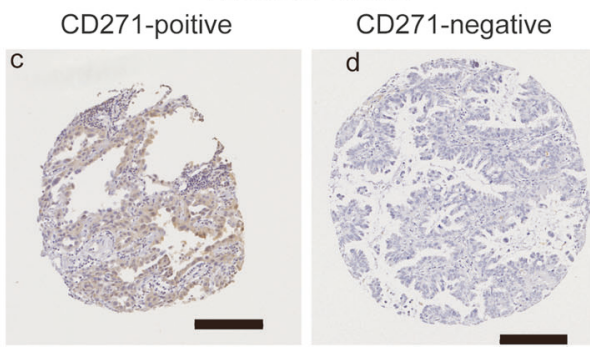

Fig. 2 a Representative images of anti-CD271 and anti-Ki67 immunohistochemically stained lung squamous cell carcinoma in situ (a-d) and lung adenocarcinoma (i-l), and representative images of antiCD271 and HE stained lung adenosquamous carcinoma (e-h) specimens obtained by surgical resection at the Miyagi Cancer Center. Bar (low-magnification images), $100 \mu \mathrm{m}$. Bar (high-magnification images), $50 \mu \mathrm{m}$. Dotted line in $\mathbf{e}$ indicates the boundary between the regions of

Table 1 CD271 is expressed in lung squamous cell carcinoma but not in lung adenocarcinoma

\begin{tabular}{llll}
\hline $\begin{array}{l}\text { CD271- } \\
\text { positive }\end{array}$ & $\begin{array}{l}\text { CD271- } \\
\text { negative }\end{array}$ & $\begin{array}{l}\text { CD271-positive } \\
\text { spcimens (\%) }\end{array}$ \\
\hline
\end{tabular}

\section{(A) MCC-TB}

$\begin{array}{llll}\text { Adenocarcinoma } & 0 & 25 & 0 \\ \begin{array}{l}\text { Adenosquamous } \\ \text { carcinoma }\end{array} & 11 & 9 & 55.0 \\ \begin{array}{l}\text { Squamous cell } \\ \text { S }\end{array} & 68 & 42 & 61.8\end{array}$

carcinoma

\section{(B) KCC-BSC}

\begin{tabular}{llll} 
Adenocarcinoma & 5 & 297 & 1.7 \\
$\begin{array}{l}\text { Squamous cell } \\
\text { carcinoma }\end{array}$ & 13 & 24 & 35.1 \\
\hline
\end{tabular}

Number of CD271-positive (>10\% positive) and CD271-negative (0-10\% positive) specimens in Miyagi Cancer Center (A) and Kanagawa Cancer Center (B) adenocarcinoma (upper left) and squamous cell carcinoma (lower right). b Representative images of anti-CD271 immunohistochemically stained lung cancer specimens obtained by surgical resection at the Kanagawa Cancer Center. a Positive staining of squamous cell carcinoma, b negative staining of squamous cell carcinoma, $\mathbf{c}$ positive staining of adenocarcinoma, and $\mathbf{d}$ negative staining of adenocarcinoma. Bar, $200 \mu \mathrm{m}$

Since CD271 is known to cooperate with Trk family proteins, we examined whether Trk was involved in the proliferation of MCC148c cells. First, the expression of Trk family molecules in MCC148c cells was evaluated by realtime PCR. TrkB expression was detectable, but little TrkA and TrkC expression was detected in MCC148c cells (data not shown). TrkB was then knocked down in MC148 cells by two TrkB-targeting siRNAs, siTrkB \#1 and \#2, and the suppression of TrkB expression was confirmed by real-time PCR (Fig. 4c). We then examined the effect of both siRNAs on the MCC148c cell proliferation in vitro using MTT assays. TrkB knockdown resulted in a slight suppression of cell proliferation, in contrast to the CD271 knockdown (Fig. 4d, dotted lines). These results indicated that CD271 plays a critical role in MCC148c cell proliferation without requiring the expression of Trk family proteins. 


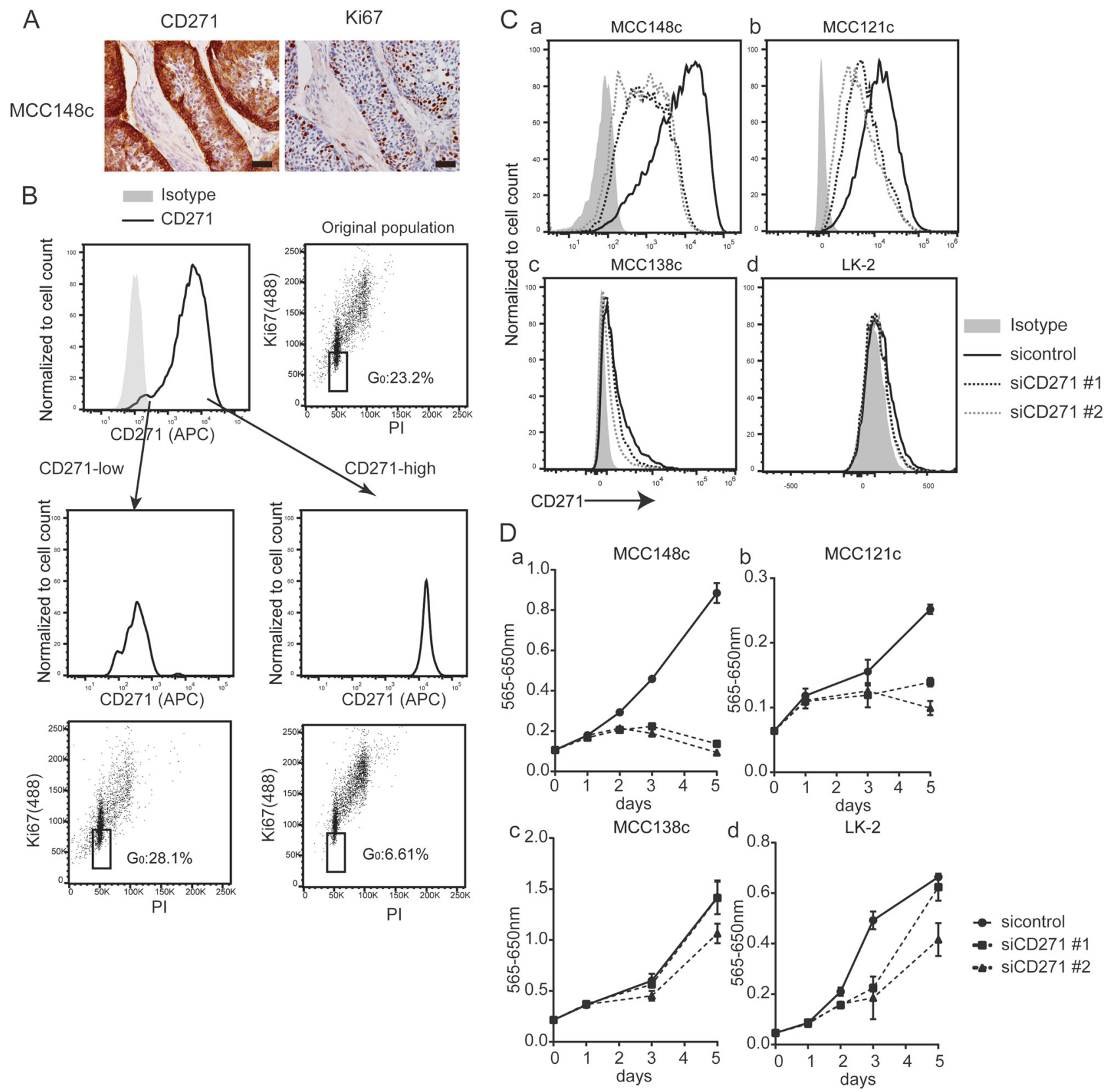

Fig. 3 a Anti-CD271 and anti-Ki67 staining of MCC148c cells. Bar, $50 \mu \mathrm{m}$. b Cell-cycle analysis of MCC148c cells. MCC148c cells were sorted into CD271 $1^{\text {high }}$ and CD271 ${ }^{\text {low }}$ cell populations by flow cytometry, and their purities were confirmed (upper). The sorted populations were then subjected to cell-cycle analysis. Percentage of cells in $\mathrm{G}_{0}$ in each cell sample is shown in the graph. PI, propidium iodide. c

\section{CD271 induces Erk phosphorylation and regulates the cell cycle}

We next, we compared the gene expression profiles between CD271-knockdown and control MCC148c cells by microarray analysis, and subjected the datasets to gene set enrichment analysis (GSEA) [15] to identify which pathway was important for cell proliferation. Seven KRAS-related
Flow cytometry analysis of the CD271-knockdown cells performed by anti-CD271 antibody staining in MCC148c (a), MCC121c (b), MCC138c (c), and LK-2 (d) cells. d Proliferation of CD271knockdown (siCD271\#1 and siCD271\#2) and sicontrol-treated MCC148c (a), MCC121c (b), MCC138c (c), and LK-2 (d) cells assessed using MTT assays $(n=5)$

pathways were included in the top 10 genes from the oncogenic signature set that were differentially expressed in the CD271-knockdown versus control MCC148c cells (Table 3). We then investigated the effect of CD271 knockdown on signaling molecules involved in the KRASrelated pathways in MCC148c cells by western blotting. The Erk phosphorylation was clearly reduced by CD271 knockdown, whereas the phosphorylations of AKT, p65, 
Fig. 4 a, b Tumor-initiating activities of MCC $148 \mathrm{c}$ cells transfected with siCD271 \#1 (a) and siCD271 \#2 (b). 100,000 cells. $(n=8)$. c MCC148c cells were transfected with siRNAs (siTrkB\#1, siTrkB\#2, and sicontrol), incubated for $48 \mathrm{~h}$, and the $\operatorname{TrkB}$ expression was determined by real-time PCR $(n=3)$. d Proliferation of TrkBknockdown (siTrkB\#1 and siTrkB\#2), CD271-knockdown (siCD271\#2), and control siRNA-treated MCC148c cells was assessed using MTT assays $(n=5)$

Table 2 CD271 knockdown decreases tumorigenicity in MCC148c cells

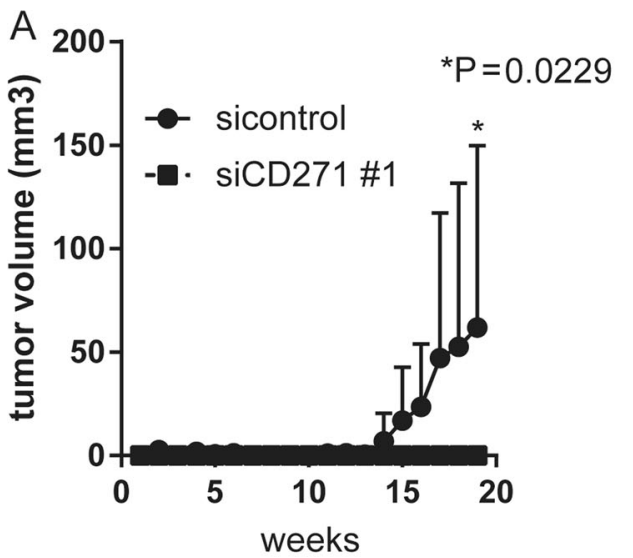

$\left.{ }^{B}{ }^{150}\right] \quad * P=0.0213$

C
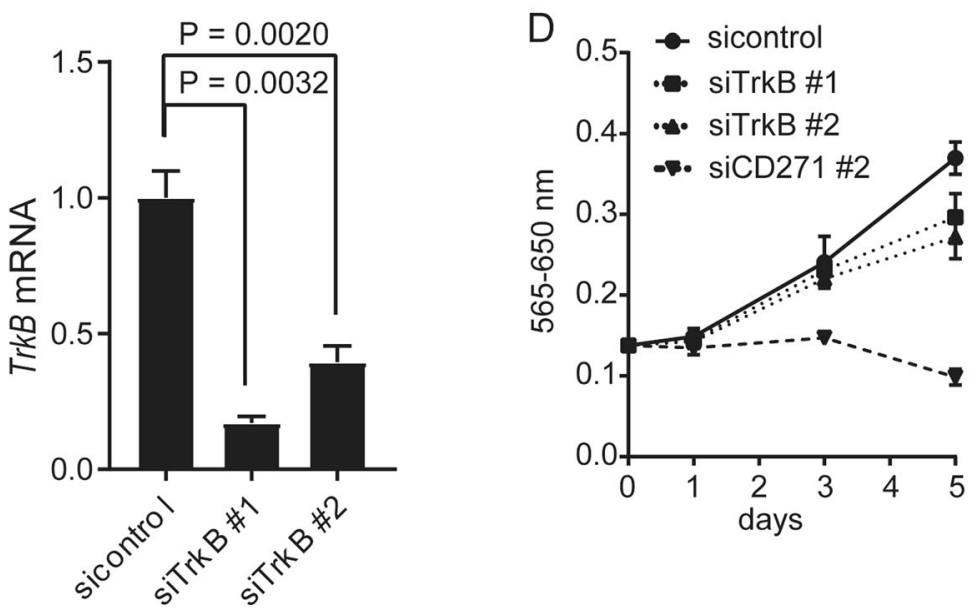

\begin{tabular}{llllllllllll}
\hline Treatment of injected cells & Number of cells injected & \multicolumn{2}{l}{ Weeks } & & 13 & 13 & \\
\cline { 3 - 10 } & & 1 & 3 & 5 & 7 & 9 & 11 & 13 & 15 & 17 & 19 \\
\hline si control & 100,000 & $0 / 8$ & $0 / 8$ & $1 / 8$ & $0 / 8$ & $0 / 8$ & $1 / 8$ & $1 / 8$ & $5 / 8$ & $7 / 8$ & $7 / 8$ \\
siCD271 \#1 & 100,000 & $0 / 8$ & $0 / 8$ & $0 / 8$ & $0 / 8$ & $0 / 8$ & $0 / 8$ & $0 / 8$ & $0 / 8$ & $0 / 8$ & $0 / 8$ \\
si control & 100,000 & $0 / 8$ & $0 / 8$ & $1 / 8$ & $0 / 8$ & $0 / 8$ & $1 / 8$ & $1 / 8$ & $4 / 8$ & $4 / 8$ & $4 / 8$ \\
siCD271 \#2 & 100,000 & $0 / 8$ & $0 / 8$ & $0 / 8$ & $0 / 8$ & $0 / 8$ & $0 / 8$ & $1 / 8$ & $0 / 8$ & $0 / 8$ & $0 / 8$ \\
\hline
\end{tabular}

Tumor-initiation capability of si-control- versus siCD271 \#1-treated and siCD271 \#2-treated MCC148c cells The number of tumors $\left(>2 \mathrm{~mm}^{3}\right)$ was indicated and $\mathrm{I} \kappa \mathrm{B} \alpha$ were unaffected (Fig. 5a). These data indicated that CD271 mainly controlled Erk phosphorylation in the KRAS-related pathway in MCC148c cells. We further analyzed the effect of an MEK-ERK inhibitor, U0126, on the ERK phosphorylation in MCC148c cells and on the proliferation of these cells. The ERK phosphorylation was clearly reduced by U0126 treatment (Fig. 5b), and the cell proliferation was partially inhibited (Fig. 5c). The immunohistochemical staining of LSCC surgical specimens showed that CD271 and phospho-ERK were coexpressed in tumor cells. (Fig. 5d). These data indicated that CD271 controls cell proliferation partially through ERK signaling.
We recently demonstrated that CD271 is involved in cell-cycle regulation in hypopharyngeal cancer [11]. Therefore, here we analyzed the cell cycle of MCC148c cells treated with siCD271\#1 and \#2. Because the MYC oncogene is known to be a key regulator of cell-cycle progression in cancer [16], we examined the $c-M y c$ expression in MCC148c cells treated with siCD271\#1 and \#2. Treatment with either siRNA significant suppressed the $c-M y c$ expression (Fig. 6a), upregulated the expression of $C D K N 1 C$, a cell-cycle-related gene, and increased the cellcycle arrest in $\mathrm{G}_{0}$ (Fig. $6 \mathrm{~b}, \mathrm{c}$ ). These data suggested that CD271 contributes to cell-cycle regulation by altering the expressions of MYC and CDKNIC. 
Table 3 CD271 knockdown induced downregulation of KRAS-related pathway

\begin{tabular}{llll}
\hline NAME & ES & $\begin{array}{l}\text { Nominal } \\
p \text {-val }\end{array}$ & $\begin{array}{l}\text { FDR } \\
q \text {-val }\end{array}$ \\
\hline KRAS.600_UP.V1_DN & -0.502 & 0.000 & 0.031 \\
KRAS.PROSTATE_UP.V1_DN & -0.508 & 0.000 & 0.032 \\
KRAS.AMP.LUNG_UP.V1_UP & -0.499 & 0.000 & 0.042 \\
KRAS.LUNG_UP.V1_DN & -0.497 & 0.003 & 0.041 \\
CAHOY_NEURONAL & -0.499 & 0.004 & 0.05 \\
KRAS.KIDNEY_UP.V1_DN & -0.491 & 0.000 & 0.053 \\
HINATA_NFKB_IMMU_INF & -0.581 & 0.075 & 0.075 \\
KRAS.600.LUNG.BREAST_UP. & -0.470 & 0.000 & 0.069 \\
V1_DN & & & \\
KRAS.LUNG.BREAST_UP.V1_DN & -0.477 & 0.006 & 0.069 \\
KRAS.300_UP.V1_DN & -0.476 & 0.003 & 0.072 \\
\hline
\end{tabular}

Gene expression data were analyzed using C6 gene sets

Characters in bold indicate KRAS-downregulated gene sets (siCD271s versus si-controls)

$E S$ enrichment score, FDR false discovery rate

\section{CD271 expression is correlated with a poor prognosis and an increased cell migration capability in LSCC}

To examine whether CD271 affects the outcome of LSCC patients, we analyzed the characteristics and prognosis of LSCC patients. A total of 110 LSCC patients in the MCCTB were evaluated. Representative pictures of CD271positive and CD271-negative specimens are shown in Fig. 7a. Table 4 summarizes the clinical and pathological characteristics of the patients in the 110 cases. CD271 expression was significantly correlated with pleural invasion (pl) and age. Since we previously reported that CD271 plays an important role in tumor migration in hypopharyngeal cancer [11], we evaluated the cell migration ability under the CD271-knock down condition. The CD271knockdown MCC148c cells exhibited significantly reduced cell motility compared to the control cells (Fig. 7b).

We introduced CD271 expression, age, gender, smoking, maximum tumor diameter, clinical stage, pathological $\mathrm{T}$ factor (pT), pN, lymphatic invasion (ly), pl, and vascular invasion (v) into a log-rank test for the univariate analysis of relapse-free-survival (Table 5), and found that CD271 expression, ly, and $\mathrm{v}$ were correlated with a poor outcome. We then introduced CD271 expression, ly and, v into a Cox regression model for the multivariate analysis of relapsefree-survival, and found that these factors were independent predictors of survival. Finally, a Kaplan-Meier analysis of relapse-free survival according to the CD271 expression (CD271-negative, weak, and strong, Supplementary Fig. S2) showed that the 5-year relapse-free survival rate was significantly lower in the CD271-strong group (Supplementary fig. S2B). This tendency became even clearer when the patients were divided into two groups, the CD271- negative group and the positive (including "strong" and "weak") group (Fig. 7c).

\section{Discussion}

We previously reported that CD271 is expressed in the basal layers of normal epithelium and in cancer in the pharynx [10], and others have also reported that CD271 is expressed in the basal layers of normal epithelium and cancer in the esophagus [12]. In this study, we further demonstrated that CD271 expression is detectable in the basal layers of normal epithelium and cancer in the lung (bronchiole and bronchus), vulva, cervix, and penis. A discrepancy in the detection rates between the MCC-TB and KCC-BSC data sets $(61.8 \%$ versus $35.5 \%)$ could have been due to the small sample size of the dataset (37 samples in $\mathrm{KCC}-\mathrm{BSC}$ versus 110 in MCC-TB) and to the staining area of the tissue samples (slides for clinical diagnosis versus smaller slides for the tissue array, respectively). These data together suggest that CD271 is generally expressed in the basal layer of epithelium and in squamous cell carcinoma derived from epithelium. In lung CIS, CD271-positive cells were distributed to the basal half of the epithelium, and Ki67 was colocalized with the CD271-positive cells. We previously reported that in the hypopharynx, the CD271positive and Ki67-positive population tended to increase from normal to increasingly cancerous tissue, dysplasia, and CIS. These data suggested that squamous cancer cell might originate from CD271-positive normal basal cells.

We also demonstrated here that CD271 was expressed specifically in lung squamous cell carcinoma (LSCC), and not in lung adenocarcinoma. While lung adenocarcinoma often arises from distal bronchioli and alveoli [17], most LSCCs arise from the airway epithelium in a main or lobar bronchus. The histopathological and gene expression analyses of mouse LSCC-like lesions revealed that LSCC resembles tracheal basal cell progenitors that are positive for KRT5 and KRT14 [18, 19]. Collectively, these data suggest that LSCC originates from basal cell progenitors.

We and others also reported that CD271 is a functional and targetable molecule in the tumor-initiating cells of oral cancer [20] and hypopharyngeal cancer [10]. We here demonstrated that CD271 is preferentially expressed in proliferating LSCC cells in vivo and in vitro and the expression of CD271 was associated with a poor prognosis. These findings suggested that CD271 is important for the proliferative capability of some types of cancer. We also previously demonstrated that CD271 expression is restricted to the dormant cells of normal epithelium and to vigorously proliferative and undifferentiated cells of severe dysplasia and malignant tissues in the hypopharynx [11]. In the normal esophagus, CD271 is known to be expressed in the mitotically quiescent basal layer [13], and 
A
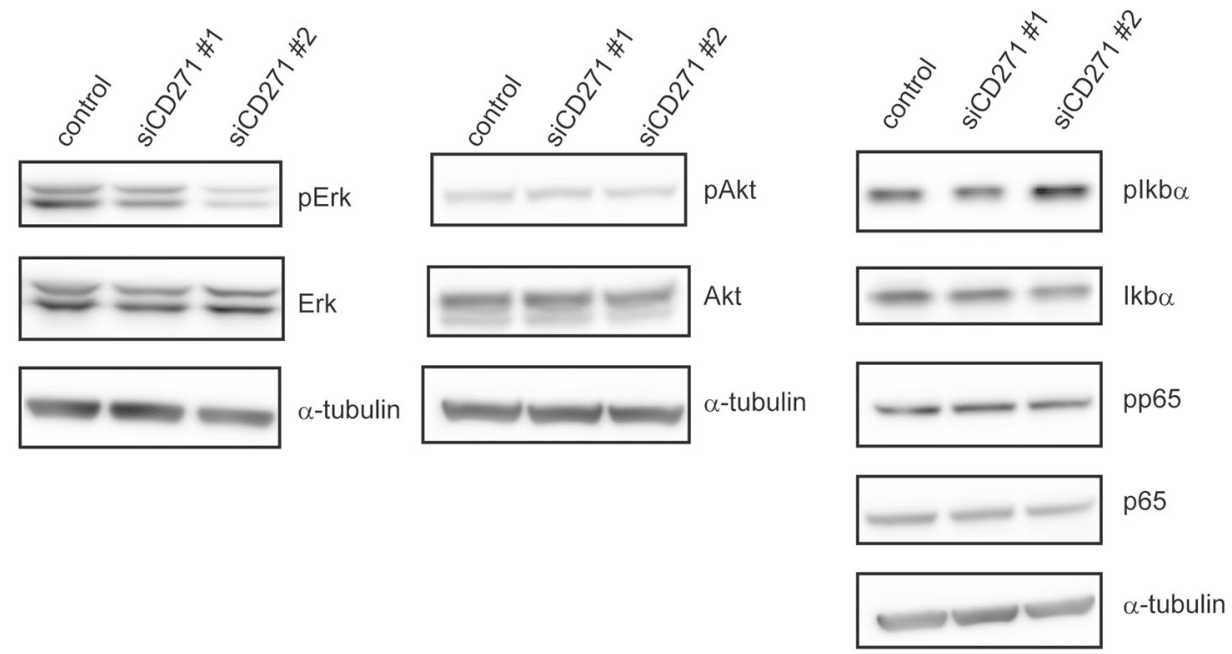

B

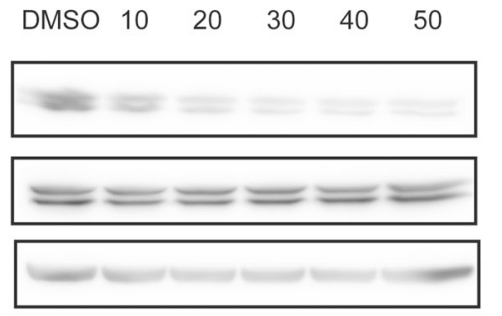

pErk

Erk

$\alpha$-tubulin
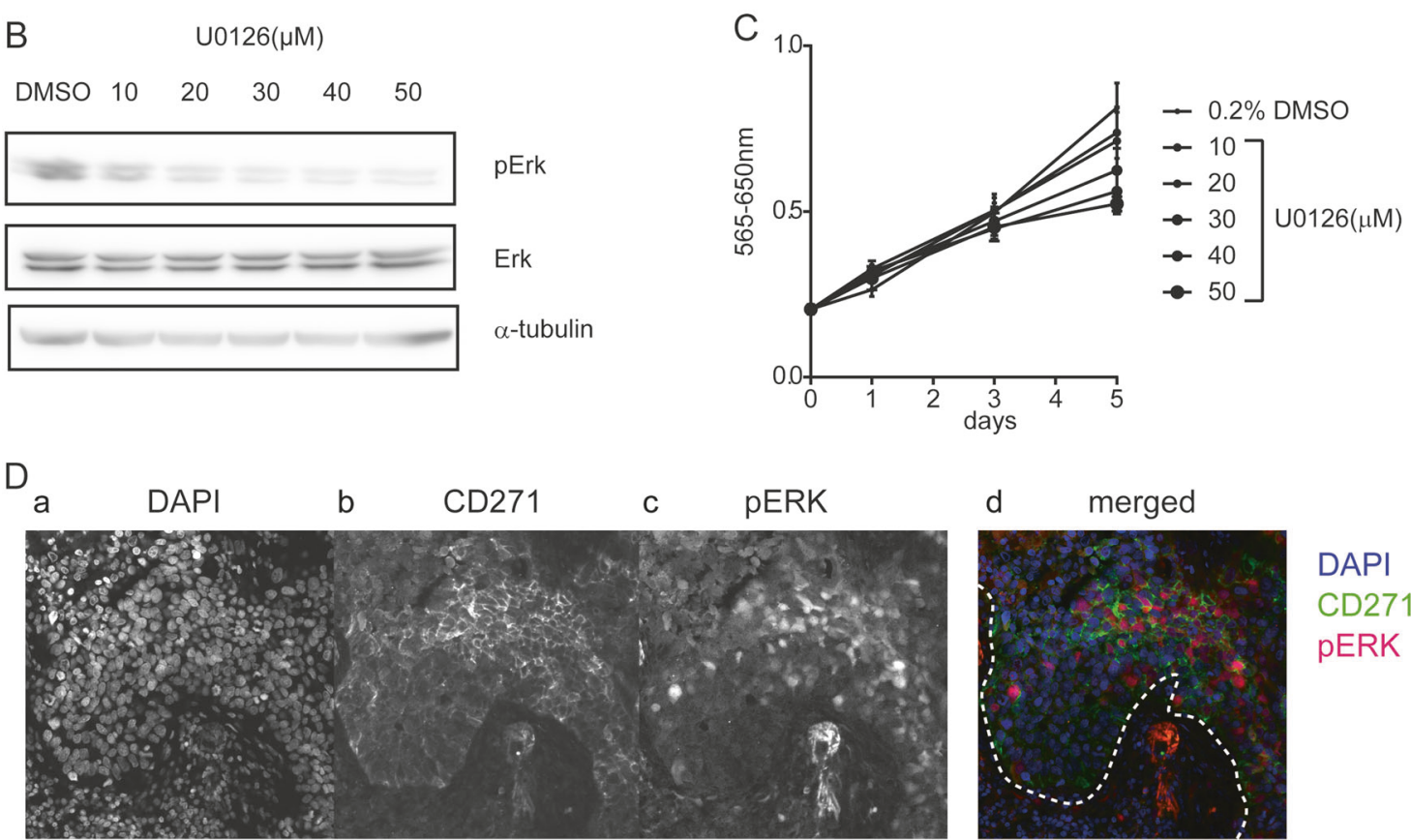

d merged

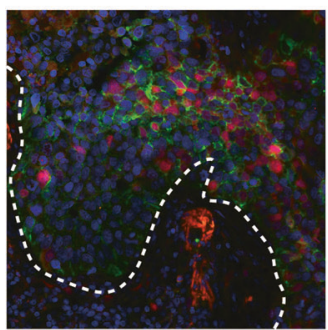

DAPI

CD271

pERK

Fig. 5 a MCC148c cells were transfected with siRNAs (siCD271\#1, $\# 2$, and sicontrol), incubated for $48 \mathrm{~h}$, and then subjected to Western blot analyses for ERK, AKT, Iкb $\alpha$, and p65 and their phosphorylated forms [p-ERK (Thr202/Tyr204), p-AKT (Ser473), p-Iкb $\alpha$ (Ser32), and pp65 (Ser536)]. b MCC148c cells were treated with U0126 for $48 \mathrm{~h}$, and then the ERK phosphorylation was analyzed by Western blotting. c MCC148c cells were treated with different concentrations of U0126

phenotypic changes from quiescent to active proliferation in the p75NTR-positive basal layer occur during the progression from low-grade to high-grade dysplasia [21]. These findings raised the possibility that $\mathrm{CD} 271$ is required for the malignant transformation of squamous epithelium cells in the lung and other organs. Because a search of the TCGA database revealed no significant cancer-related change in the CD271 gene expression, some upstream mediator of CD271 could change through the malignant transformation of squamous epithelial cells. Further study using mouse carcinogenesis
( $n=5$ each $)$ and subjected to proliferation assays. d Representative images of the immunofluorescence staining of LSCC surgical specimens. Immunostaining was performed with anti-CD271 (b) and antiphospho-ERK (pERK, c) antibodies and DAPI (d). Merged image is shown in $\mathbf{d}$. Dotted line indicates the boundary between the regions of the LSCC (upper right) and stroma (lower left)

models and a CD271-tracking system will be required to elucidate how CD271 is involved in the development of LSCC and other SCCs.

It is well-known that CD271 binds Trk family proteins to form a high-affinity receptor for ligands (NGF, BDNF, NT3, and NT4), and that after ligand binding, the Trks contribute to signaling that activates RAS and ERK [6]. In head and neck squamous cell carcinoma, a previous report demonstrated that NGF, one of CD271 ligands, promotes cell proliferation [22]. However, in a preliminary study we found no clear 
A

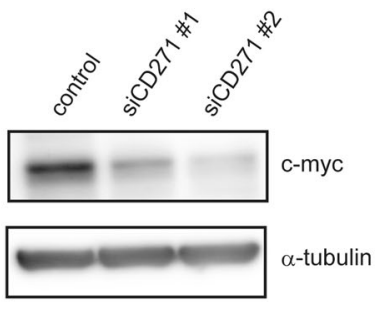

C

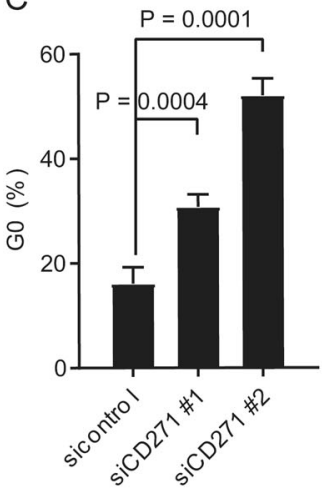

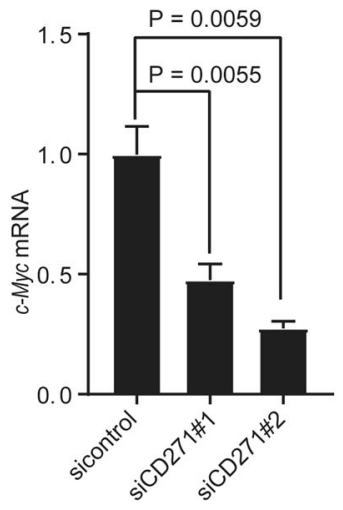

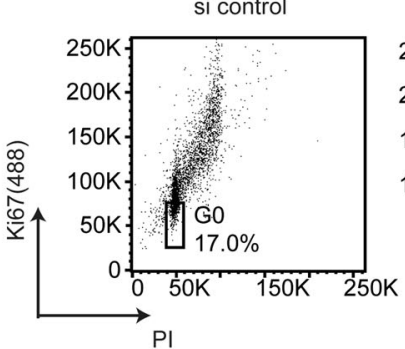

B

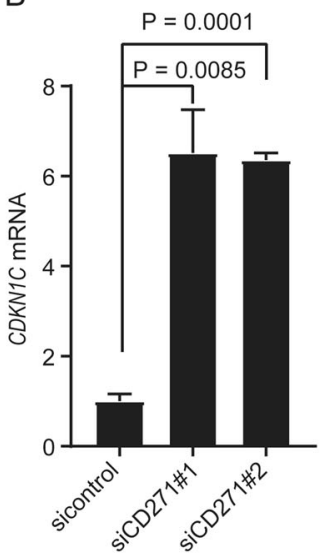

Fig. 6 a MCC148c cells were transfected with siRNAs (siCD271\#1, $\# 2$, and sicontrol), incubated for $48 \mathrm{~h}$, and then subjected to Western blot (left) and real-time PCR analyses (right, $n=3$ ) for c-Myc. b Expression profile of $C D K N 1 C$ in CD271-knockdown and control
MCC148c cells analyzed using real-time PCR $(n=3)$. c Cell-cycle analysis of CD271-knockdown cells performed using Ki67 and PI staining. Percentage of cells in $G_{0}$ is shown $(n=3)$
Fig. 7 a Representative images of CD271-negative and CD271positive LSCC samples. Bar, 50 $\mu \mathrm{m}$. b Scratch assay. Confluent MCC148c cells were scratched with a pipette just after they were transfected with siCD271\#1 or \#2 or sicontrol, and the scratched areas were measured at 0 and $24 \mathrm{~h}$ of culture. Graph shows the quantified migrated areas (arbitrary units, A.U.). $(n=4)$. c Kaplan-Meier analysis for relapse-free survival of the "CD271-negative" and "CD271positive" groups. The p-value was calculated by the log-rank test. The color version of these figures are shown in Supplementary Fig. S3
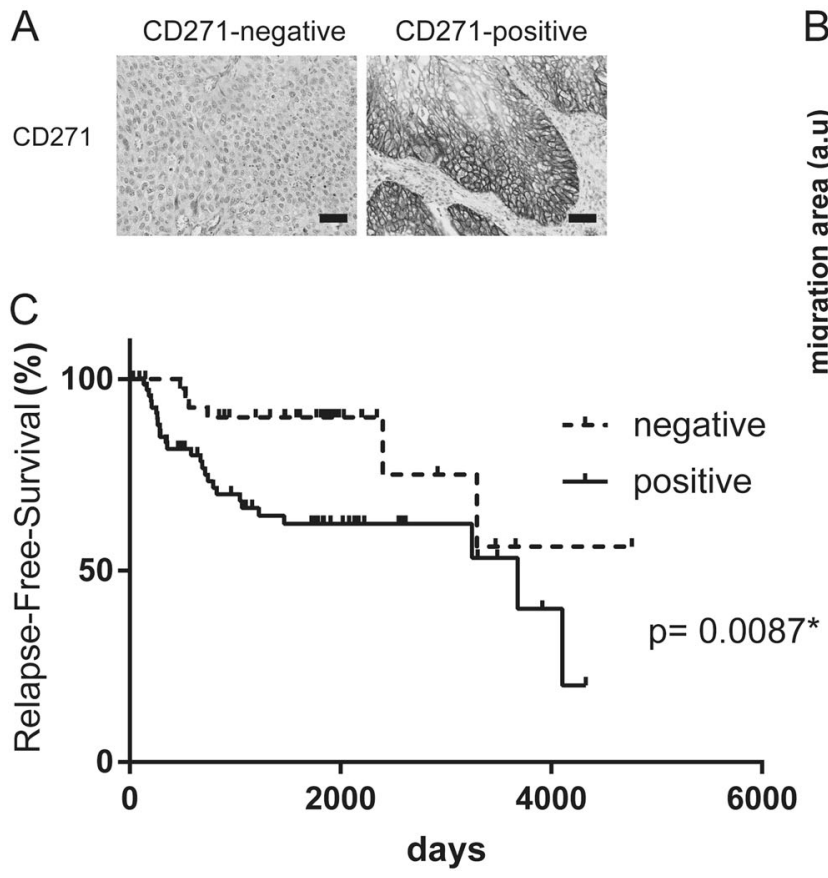

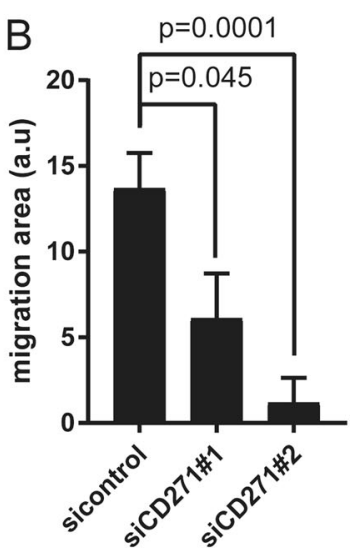


Table 4 Characteristics of patients with lung squamous cell carcinoma

\begin{tabular}{|c|c|c|c|}
\hline Parameter & $\begin{array}{l}\text { CD271-negative } \\
(n=42)\end{array}$ & $\begin{array}{l}\text { CD271-positive } \\
(n=68)\end{array}$ & $p$-value \\
\hline $\begin{array}{l}\text { Age mean } \\
\text { (range) }\end{array}$ & $68.26(48-81)$ & $71.28(51-88)$ & $0.01152 *$ \\
\hline \multicolumn{4}{|l|}{ Gender } \\
\hline Male & 39 & 64 & n.s. \\
\hline Female & 3 & 4 & \\
\hline $\begin{array}{l}\text { Smoking } \\
\text { index }\end{array}$ & 1030.19 & 991.59 & 0.716 \\
\hline $\begin{array}{l}\text { Max tumor } \\
\text { diameter } \\
(\mathrm{mm})\end{array}$ & 32.21 & 36.72 & 0.1955 \\
\hline \multicolumn{4}{|l|}{ Stage } \\
\hline 1 & 26 & 44 & 0.8228 \\
\hline 2 & 13 & 18 & \\
\hline $2<$ & 3 & 6 & \\
\hline \multicolumn{4}{|l|}{ pT } \\
\hline 1 & 19 & 21 & 0.3671 \\
\hline 2 & 19 & 39 & \\
\hline $2<$ & 4 & 8 & \\
\hline \multicolumn{4}{|l|}{$\mathrm{pN}$} \\
\hline 0 & 34 & 55 & n.s. \\
\hline $1 \leq$ & 7 & 12 & \\
\hline $\mathrm{x}$ & 1 & 1 & \\
\hline \multicolumn{4}{|l|}{$\mathrm{pM}$} \\
\hline 0 & 42 & 68 & n.s. \\
\hline 1 & 0 & 0 & \\
\hline \multicolumn{4}{|l|}{ ly } \\
\hline 0 & 38 & 64 & 0.4779 \\
\hline 1 & 4 & 4 & \\
\hline \multicolumn{4}{|l|}{$\mathrm{v}$} \\
\hline 0 & 22 & 42 & 0.4265 \\
\hline $1 \leq$ & 20 & 26 & \\
\hline \multicolumn{4}{|l|}{$\mathrm{pl}$} \\
\hline 0 & 37 & 41 & $0.002218 * *$ \\
\hline $1 \leq$ & 5 & 27 & \\
\hline
\end{tabular}

Clinicopathologic parameters of lung squamous cell carcinoma patients in the MCC $(n=110)$. $p$-values were calculated by Fisher's exact test or Welch's $t$-test.

pTNM pathological tumor nodes metastasis classification, $p l$ pleural invasion, $l y$ Lymphatic invasion, $v$ vascular invasion

relationship between various ligands (NGF, BDNF, NT3, and NT4) and cell proliferation in CD271-expressing LSCC cells (data not shown). Although the mechanism of the CD271mediated cell proliferation of SCCs is still unclear, CD271 is a potential therapeutic target for at least LSCC and hypopharyngeal carcinomas, because its knockdown induced a complete inhibition of cell proliferation in these cancers.

In this study, we found that age and pl factor were significantly correlated with the expression of CD271. We further demonstrated that age was not a risk factor in our dataset, whereas CD271, ly, and v were significantly related to relapse-free survival. These data suggested that CD271 is a powerful prognostic factor in lung SCC. The limitation of our study is that it was not a prospective cohort study analyzing the prognosis of lung cancer patients. Further
Table 5 Log rank test and cox hazard analysis of relapse-free survival

\begin{tabular}{|c|c|c|c|c|c|}
\hline \multirow[t]{2}{*}{ Parameter } & \multicolumn{2}{|c|}{ Log-rank test } & \multicolumn{3}{|c|}{ Cox's hazard model } \\
\hline & $n$ & $p$-value & HR & $95 \% \mathrm{Cl}$ & $p$-value \\
\hline \multicolumn{6}{|l|}{ CD271 } \\
\hline Negative & 42 & $0.009 * *$ & 4.3307 & $1.725-10.874$ & $0.00181 * *$ \\
\hline Positive & 68 & & & & \\
\hline \multicolumn{6}{|l|}{ Age } \\
\hline$<71.5$ & 55 & 0.2 & - & - & - \\
\hline $71.5 \leq$ & 55 & & & & \\
\hline \multicolumn{6}{|l|}{ Gender } \\
\hline Male & 103 & 0.6 & - & - & - \\
\hline Female & 7 & & & & \\
\hline \multicolumn{6}{|c|}{ Smoking index } \\
\hline$<880$ & 55 & 0.3 & - & - & - \\
\hline $880 \leq$ & 55 & & & & \\
\hline \multicolumn{6}{|c|}{ Max tumor diameter (mm) } \\
\hline$<33$ & 55 & 0.4 & - & - & - \\
\hline $33 \leq$ & 55 & & & & \\
\hline \multicolumn{6}{|l|}{ Stage } \\
\hline 1 & 70 & 0.6 & - & - & - \\
\hline $2 \leq$ & 40 & & & & \\
\hline \multicolumn{6}{|l|}{$\mathrm{pT}$} \\
\hline 1 & 40 & 0.8 & - & - & - \\
\hline $2 \leq$ & 70 & & & & \\
\hline \multicolumn{6}{|l|}{$\mathrm{pN}$} \\
\hline 0 & 89 & 0.8 & - & - & - \\
\hline $1 \leq$ & 19 & & & & \\
\hline $\mathrm{x}$ & 2 & - & & & \\
\hline \multicolumn{6}{|l|}{ ly } \\
\hline 0 & 102 & $0.01 *$ & 4.6995 & $1.740-12.694$ & $0.00227 * *$ \\
\hline 1 & 8 & & & & \\
\hline \multicolumn{6}{|l|}{$\mathrm{v}$} \\
\hline 0 & 64 & $0.04 *$ & 2.7202 & $1.330-5.565$ & $0.00614 * *$ \\
\hline $1 \leq$ & 46 & & & & \\
\hline \multicolumn{6}{|l|}{$\mathrm{pl}$} \\
\hline 0 & 78 & 0.6 & - & - & - \\
\hline $1 \leq$ & 32 & & & & \\
\hline
\end{tabular}

Univariable analysis by log-rank test and multivariable analysis by Cox's hazards model

studies aimed at establishing a CD271-targeting therapy in squamous cell carcinoma are warranted.

Acknowledgements This research was supported in part by JSPS KAKENHI Grant Numbers JP: 16K20290, 18K09363, KUROKAWA CANCER RESEARCH FOUNDATION, Intelligent Cosmos Academic Foundation, the Biomedical Research Core of Tohoku University Graduate School of Medicine and Grant-in-Aid for Scientific Research on Innovative Areas from The Japan Society for the Promotion of Science (JSPS KAKENHI Grant Number JP: 16H06277).

\section{Compliance with ethical standards}

Conflict of interest The authors declare that they have no conflict of interest. 
Publisher's note: Springer Nature remains neutral with regard to jurisdictional claims in published maps and institutional affiliations.

\section{References}

1. Siegel RL, Miller KD, Jemal A. Cancer statistics, 2017. Cancer J Clin. 2017;67:7-30.

2. Sawabata N, Asamura H, Goya T, et al. Japanese Lung Cancer Registry Study: first prospective enrollment of a large number of surgical and nonsurgical cases in 2002. J Thorac Oncol. 2010;5:1369-75.

3. Zappa C, Mousa SA. Non-small cell lung cancer: current treatment and future advances. Transl Lung Cancer Res. 2016;5:288-300.

4. Gandara DR, Hammerman PS, Sos ML, et al. Squamous cell lung cancer: from tumor genomics to cancer therapeutics. Clin Cancer Res. 2015;21:2236-43.

5. Morgensztern D, Waqar S, Subramanian J, et al. Improving survival for stage IV non-small cell lung cancer: a surveillance, epidemiology, and end results survey from 1990 to 2005. J Thorac Oncol. 2009;4:1524-9.

6. Chao MV. Neurotrophins and their receptors: a convergence point for many signalling pathways. Nat Rev Neurosci. 2003;4:299-309.

7. Chao MV, Hempstead BL. p75 and Trk: a two-receptor system. Trends Neurosci. 1995;18:321-6.

8. Bibel M, Hoppe E, Barde YA. Biochemical and functional interactions between the neurotrophin receptors trk and p75NTR. EMBO J. 1999; 18:616-22.

9. Ozono K, Ohishi Y, Onishi H, et al. Brain-derived neurotrophic factor/tropomyosin-related kinase B signaling pathway contributes to the aggressive behavior of lung squamous cell carcinoma. Lab Invest. 2017;97:1332-42.

10. Imai T, Tamai K, Oizumi S, et al. CD271 defines a stem cell-like population in hypopharyngeal cancer. PLoS ONE. 2013;8: e62002.
11. Mochizuki M, Tamai K, Imai T, et al. CD271 regulates the proliferation and motility of hypopharyngeal cancer cells. Sci Rep. 2016:6:30707.

12. Okumura T, Tsunoda S, Mori Y, et al. The biological role of the low-affinity p75 neurotrophin receptor in esophageal squamous cell carcinoma. Clin Cancer Res. 2006;12:5096-103.

13. Yamaguchi T, Okumura T, Hirano K, et al. p75 neurotrophin receptor expression is a characteristic of the mitotically quiescent cancer stem cell population present in esophageal squamous cell carcinoma. Int J Oncol. 2016;48:1943-54.

14. Matouk IJ, DeGroot N, Mezan S, et al. The H19 non-coding RNA is essential for human tumor growth. PLoS ONE. 2007;2:e845.

15. Subramanian A, Tamayo P, Mootha VK, et al. Gene set enrichment analysis: a knowledge-based approach for interpreting genome-wide expression profiles. Proc Natl Acad Sci USA. 2005;102:15545-50.

16. Dang CV. MYC on the path to cancer. Cell. 2012;149:22-35.

17. Bonastre E, Brambilla E, Sanchez-Cespedes M. Cell adhesion and polarity in squamous cell carcinoma of the lung. $\mathrm{J}$ Pathol. 2016;238:606-16.

18. Sutherland KD, Berns A. Cell of origin of lung cancer. Mol Oncol. 2010;4:397-403.

19. Hanna JM, Onaitis MW. Cell of origin of lung cancer. J Carcinog. 2013;12:6.

20. Murillo-Sauca O, Chung MK, Shin JH, et al. CD271 is a functional and targetable marker of tumor-initiating cells in head and neck squamous cell carcinoma. Oncotarget. 2014;5:6854-66.

21. Okumura T, Shimada Y, Sakurai T, et al. Abnormal cell proliferation in the p75NTR-positive basal cell compartment of the esophageal epithelium during squamous carcinogenesis. Dis Esophagus. 2015;28:634-43.

22. Dudas J, Dietl W, Romani A, et al. Nerve growth factor (NGF)receptor survival axis in head and neck squamous cell carcinoma. Int J Mol Sci 2018;19(6). pii: E1771.

\section{Affiliations}

\section{Mai Mochizuki ${ }^{1} \cdot$ Mao Nakamura ${ }^{2} \cdot$ Rie Sibuya $^{1} \cdot$ Toshimasa Okazaki $^{3} \cdot$ Jiro Abe $^{3} \cdot$ Takayuki Nakagawa $^{1} \cdot$}

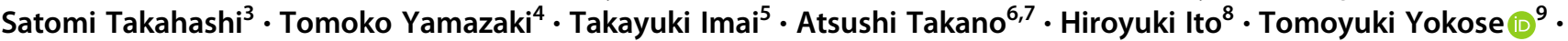
Yohei Miyagi ${ }^{10} \cdot$ Yataro Daigo $^{6,7} \cdot$ Ikuro Sato $^{11} \cdot$ Kennichi Satoh $^{1,12} \cdot$ Kazuo Sugamura $^{2} \cdot$ Kazunori Yamaguchi $^{2}$. Keiichi Tamai ${ }^{1}$

1 Division of Cancer Stem Cell, Miyagi Cancer Center Research Institute, Natori, Japan

2 Division of Molecular and Cellular Oncology, Miyagi Cancer Center Research Institute, Natori, Japan

3 Department of Thoracic Surgery, Miyagi Cancer Center, Natori, Japan

4 Department of Head and Neck Medical Oncology, Miyagi Cancer Center, Natori, Japan

5 Department of Head and Neck Surgery, Miyagi Cancer Center, Natori, Japan

6 Center for Antibody and Vaccine Therapy, Research Hospital, Institute of Medical Science, The University of Tokyo, Tokyo, Japan
7 Department of Medical Oncology and Cancer Center, Shiga University of Medical Science, Otsu, Japan

8 Department of Thoracic Surgery, Kanagawa Cancer Center, Yokohama, Japan

9 Department of Pathology, Kanagawa Cancer Center, Yokohama, Japan

10 Molecular Pathology and Genetics Division, Kanagawa Cancer Center Research Institute, Yokohama, Japan

11 Department of Pathology, Miyagi Cancer Center, Natori, Japan

12 Division of Gastroenterology and Hepatology, Tohoku Medical and Pharmaceutical University, Sendai, Japan 